\title{
The Behavior of the Components of M3 in the Euro Area: 1999-2014
}

\author{
Carlos Pateiro-Rodríguez ${ }^{1}$, Esther Barros-Campello¹, Laura Varela Candamioํ, Carlos Pateiro-López² \\ ${ }^{1}$ Faculty of Economics and Business, University of A Coruña, A Coruña, Spain \\ ${ }^{2}$ Law School, University of A Coruña, A Coruña, Spain \\ Email: carlos.pateiro@udc.es
}

How to cite this paper: Pateiro-Rodríguez, C., Barros-Campello, E., Candamio, L.V. and Pateiro-López, C. (2016) The Behavior of the Components of M3 in the Euro Area: 1999-2014. Open Journal of Business and Management, 4, 606-620.

http://dx.doi.org/10.4236/ojbm.2016.44062

Received: July 15, 2016

Accepted: August 22, 2016

Published: August 25, 2016

Copyright $\odot 2016$ by authors and Scientific Research Publishing Inc. This work is licensed under the Creative Commons Attribution International License (CC BY 4.0).

http://creativecommons.org/licenses/by/4.0/

\begin{abstract}
In this paper, the evolution of the various components of the broad monetary aggregate $\mathrm{M} 3$ at which the ECB attaches leading indicator properties of inflation expectations in the euro area is studied. During the fifteen years that the ECB defines and executes the stability-oriented monetary policy, M3 has not followed the developments that initially would be compatible with the inflation target announced. For its part, the components of the aggregate, in terms of their participation in it, have followed different paths. In this paper, an analysis of stationarity and cointegration of the series is done. The causes of such behavior in the light of the evolution of prices, interest rates and economic growth are searched, using dummy variables for periods of greater instability in the financial markets. We employ the Dynamic Ordinary Least Square (DOLS) estimator, augmenting the estimated relation with lead and lag differences of the explanatory variables to control for endogeneity and serial correlation of the regressors.
\end{abstract}

\section{Keywords}

Monetary Aggregates, ECB, Interest Rates, Monetary Policy

\section{Introduction}

In October and December 1998, the Governing Council of the European Central Bank (ECB) made public the main elements of its monetary policy strategy, whose ultimate objective was price stability (ECB, 1999a) [1]. The ECB participates in the broad consensus in the economics profession about the monetary origins of inflation. ECB (2000) [2] itself assumes that one of the most remarkable empirical regularities in macroeconomics is the ubiquitous long-term relationship between the price level and the money stock. The monetary origins of inflation are the subject of widespread consensus in the 
economics profession.

This relationship between money supply and prices is deducted from the quantity equation of money in its classic version. With certain assumptions about the economic growth rate and the velocity of circulation of the broad monetary aggregate M3, the relationship between money supply growth and prices can be set for a specific inflation target. This is essentially the approach of the ECB when setting a reference value of $4.5 \%$ a year, three-month moving average for the growth of the broad monetary aggregate M3, according to the modern version of the quantity equation of money, for a target of inflation around $2 \%$.

When fifteen years have passed since the ECB defines and implements, the monetary policy of the euro zone is of interest the analysis of developments in M3 and its various components during this period. As discussed in the following sections, the monetary aggregate chosen as reference not behaved as the Bank itself declared compatible with an inflation target of $2 \%$. Overall, the ECB is entitled to considerable success in controlling inflation in the Euro zone, despite the significant deviations of the aggregate monetary M3 relative to the reference values established. A profound observation of the evolution of each of the components of M3, from September 1997 until December 2014, may shed light on the fulfillment of the established empirical regularity, according to which inflation has a monetary origin. Possibly we are facing one of the cases already signed by Poole (1994) [3] who argues the weakness of the relationship between money and prices in economies of low and stable inflation against a high and reliable relationship in those where inflation exceeds two or three digits. The origin of potential divergences in the relationship between money and prices under two possible modes of inflation (low and stable against high and unstable) may be behind the behavior of the private sector or the objectives and implementation of monetary policy.

The aim of this paper is the search for the relationship between each of the components of the monetary aggregate M3 and some of the macroeconomic variables that economic literature states as more stable determinants of money demand. Although the relationship between the broad aggregate and these variables is analyzed, our approach is rather on each of its seven components, from the most liquid to least liquid. In this way, we can detect a possible change in behavior of economic agents in the euro zone for the first fifteen years of ECB experience extending through a first stage of rapid construction of reputation, an intermediate stage of stability and growth and a final period of great economic and financial instability. In this last phase, the ECB, like the Federal Reserve, took steps to measures of unconventional monetary policy easing (quantitative easing) in order to boost credit.

From this work, we obtain three main conclusions: 1) Agents increased the proportion of currency in circulation with regard to M3 continuously for the past fifteen years. The same trend is observed in overnight deposits, albeit with significant swings since mid-2006 until mid-2010. The sum of the two most liquid components (constituting the narrow money, M1) has increased from $36 \%$ at the end of 2007 to $57.5 \%$ at the end of 2014. 2) The deposits with agreed maturity of up to two years and deposits redeemable at notice of up to three months show a mild downward trend. The sum of both, 
which represented $48.6 \%$ of M3 in late 2007, decreased to 36.5\% in December 2014 and

3) The remaining three components, whose quantitative significance is less, have a smooth downward trend over period analyzed, reducing their combined share of M3 from $14.2 \%$ in late 1997 to $6.2 \%$ in December 2014.

The paper is organized as follows. After the introduction, in Section 2 we analyze the properties of the data series, both in absolute terms and in terms of their participation in the broad money (M3). Augmented Dickey-Fuller (ADF) and Phillips-Perron (PP) tests were used as unit root tests to detect the degree of integration of the series. In Section 3, data series are subjected to Johansen cointegration test in order to correctly interpret the results of the regression analysis of Section 4, due to the potential presence of spurious regression when it is used non-stationary data series. Section 5 , a regression analysis with the Stock Watson Dynamic (DOLS) [4] method is proposed and we compare the results obtained with the Ordinary Least Squares (OLS) method. Finally, a last section is devoted to conclusions.

\section{Literature Review}

The empirical evidence on the behavior of each of the components of broad money is not very numerous. However, there is an extensive literature on the study of the demand for money using time-series techniques (Capasso and Napolitano, 2012) [5]. Recently, panel data methodologies were used under the pretext of saving some problems arising in the works with time series (Mulligan and Sala-i-Martin, 1992) [6]. The approach and the use of similar techniques to those addressed in this work have been applied in this field to study the income elasticity of demand for money whether it is used as a proxy for the demand for money, narrow money (M1), intermediate money (M2) or broad money (M3). Among others, Setzer and Wolff (2013) [4] use dynamic regression (DOLS). Nautz and Rondorf (2011) [7] adopt an Auto Regressive Distributed Lag model (ARDL); Foresti and Napolitano (2013) [8] use panel data to study the demand for money in the long term; Dreger, Reimers and Roffia (2007) [9] used the Pedroni, Breitung and DOLS technique to a panel of 10 new countries into European Monetary Union (EMU). Using co-integration and DOLS, and Arnold and Roeland (2010) [10] and Hamori and Hamori (2008) [11], respectively, study the income elasticity of demand for money to M3 and M1 in the EU. Mark and Sul (2003) [12] perform dynamic estimates (DOLS) income elasticity of demand for money for 27 OECD countries; Rao, Tamazian and Singh (2009) [13] do so for 11 countries in Asia using the generalized method of moments (GMM). Hamori and Tokihisa (2001) [14] study the seasonal cointegration in the function of the demand for money, and the evidence for Japan. The semi-elasticity-interest rate was studied, among others, by Harb (2004) [15] and Dreger and Wolters (2010) [16].

Other works focused on the study of the stability of money demand in the EMU and discovered instability M3 against the assumption of stability the ECB itself (1999b) [17]; among others, Beyer, Fischer and Landesberger (2007) [18], Fischer, Lenza, Pill and Reichlin (2007) [19], Gerlach and Svensson (2003) [20]. The importance of monetary aggregates in the euro area was studied by Forresti and Napolitano (2014) [21]. 


\section{The Properties of the Data}

\subsection{The Data}

Database of monetary aggregates correspond to the components of M3, as they are defined by the ECB itself. The ECB's definitions of euro area monetary aggregates are based on a harmonized definition of the money-issuing sector and the money-holding sector, as well as of harmonized categories of MFI liabilities. Based on conceptual considerations and empirical studies, and in line with international practice, the Eurosystem has defined a narrow (M1), an "intermediate" (M2) and a broad monetary aggregate (M3). These aggregates differ with regard to the degree of liquidity (as assessed on the basis of the criteria of transferability, convertibility, price certainty and marketability) of the assets they include.

M1 comprises currency in circulation and overnight deposits, which can be immediately converted into currency or used for cashless payments. M2 includes, in addition, deposits that can be converted into components of narrow money, although some restrictions may apply, such as the need for advance notification, penalties and fees. Finally, M3 comprises M2 and certain marketable instruments issued by the resident MFI sector. A high degree of liquidity and price certainty make these instruments close substitutes for deposits. Table 1 set out the definitions of euro area monetary aggregates.

The data relating to production are the rate of change of the Industrial Production Index (IPI) because, being a monthly series, it is perfectly compatible with the monetary series and those of interest rates and prices. The interest rates used are the main refinancing operation interest rate (MROR) of the ECB, the Eonia, three-month Euribor and one-year Euribor; all relevant data on the monthly average rate. As inflation the rate of change in monthly data of the Harmonized Consumer Price Index (HCPI) in the euro zone is used. The data source is also the ECB. All data are extracted from the database of ECB. Table 2 contains the description of the variables of production, prices and interest rates.

\subsection{The Statistical Analysis of Series}

First we submit the data series testing ADF and PP unit roots in levels and in first differences, based on the work of Dickey and Fuller (1979) [22] and Phillips and Perron

Table 1. Definitions of euro area monetary aggregates.

\begin{tabular}{cccccc}
\hline Liabilities & M1 & M2 & M3 & Variable & \%/M3 \\
\hline Currency in circulation & X & X & X & CIC & Par CIC \\
Overnight deposits & X & X & X & OD & Par OD \\
Deposits with an agreed maturity of up to 2 years & & X & X & DAM & Par DAM \\
Deposits redeemable at notice of up to 3 months & X & X & DRN & Par DRN \\
Repurchase agreements & & & X & MMF & Par MMF \\
Money market fund shares/units & & & X & REP & Par REP \\
Deb securities issued with a maturity of up to 2 year & & & X & DS & Par DS \\
\hline
\end{tabular}


(1988) [23].

The results presented in Table 3 show that M3 and each of its components in levels are not stationary or random walks. In first differences all series are stochastic processes I (0), i.e., are stationary series. We can say, then, that M3 and each of its seven components are integrated series of order one I (1) in levels.

The notation of the series is as follows: M3 broad monetary aggregate M3; CIC currency in circulation; OD overnight deposits; DAM deposits with agreed maturity of up to two years; DRN deposits redeemable at notice of up to three months; MMF money market funds shares; RPA repurchase agreements; DS debt securities of up to two years.

As it was expected, both the broad monetary aggregate M3 as each of its components, except for repurchase agreements, have had a growing trend during the period. The $\mathrm{ADF}$ and PP tests show that all series are nonstationary in levels and stationary in first differences. Regarding the slope of the linear fit each series has a positive slope, except

Table 2. Production, prices, interest rates.

\begin{tabular}{ccc}
\hline Data & Series & Variable \\
\hline Production & Industrial production index & IPI \\
Consum. prices & Rate of change in monthly data of harmonized consume price index & Inflation \\
Of. Interest rate & The main refinancing operation interest rate & MROR \\
Interbank interest rate & Euro overnight interest rate EONIA & Eonia \\
& Three-month Euribor interest rate & Eurb 3 m \\
Unemployment & One year Euribor interest rate & Eurb 1 y \\
Core inflation & Monthly unemployment rate & Unemp \\
\hline
\end{tabular}

Table 3. ADF and PP tests of M3 and its components.

\begin{tabular}{cccccl}
\hline \multirow{2}{*}{ Series } & \multicolumn{2}{c}{ Levels } & \multicolumn{2}{c}{ First differences } & Trend \\
\cline { 2 - 5 } & ADF & PP & ADF & PP & \\
\hline M3 & -2 & -1.07 & -10.51 & -12.07 & Positive \\
CIC & -2.32 & -2.29 & -11.10 & -12.20 & Positive \\
OD & -1.12 & -1.94 & -12.62 & -12.93 & Positive \\
DAM & -0.92 & -1.29 & -6.22 & -7.07 & Positive \\
DRN & -1.43 & -1.75 & -11.92 & -12.59 & Positive \\
MMF & -0.27 & -0.056 & -11.82 & -12.81 & Positive \\
REP & -1.35 & -1.30 & -10.46 & -14.4 & Negative \\
DS & -1.48 & -1.30 & -13.87 & -13.31 & Positive \\
& C. V. MacKinnon & & C. V. MacKinnon & \\
& $1 \%, 5 \%, 10 \%$ & & \multicolumn{2}{c}{$1 \%, 5 \%, 10 \%$} & *Very reduced \\
& $-4 ;-3.43 ;-3.139$ & & $-3.46 ;-2.87 ;-2.57$ & \\
\hline
\end{tabular}


repurchase agreements. For its part, the MMF and DS series, although present positive trend, it is very low, which allows us to say that the RPA, MMF and DS components have hardly changed over the last fifteen years or did it gently.

Secondly, we perform similar work with the series representing the participation of each of the seven components in the monetary aggregate M3. Table 4 shows the results of the ADF and PP tests, both in levels and in first differences.

As in the previous case, all the representative series of participation of each component in the M3 aggregate, in levels, have the characteristics of nonstationary series. In first differences series are stochastic processes I (0). Consequently, the series in levels are integrated of order 1, or I (1). At this point we must bring out that only the first two components of Table 4, i.e., the share of currency in circulation and the share of overnight deposits have positive trend, as can be seen in Figure 1. The remaining five ones have been reducing their participation in M3 over the period studied. The participation

Table 4. ADF and PP tests of the participation of the components in M3.

\begin{tabular}{cccccc}
\hline \multirow{2}{*}{ Series } & \multicolumn{2}{c}{ Levels } & \multicolumn{2}{c}{ First differences } & Trend \\
\cline { 2 - 5 } & ADF & PP & ADF & PP & \\
\hline Par CIC & -1.26 & -1.84 & -11.89 & -12.94 & Positive \\
Par OD & -1.11 & -1.64 & -9.02 & -7.45 & Positive \\
Par DAM & -0.79 & -1.09 & -10.88 & -11.78 & Negative \\
Par DRN & -2.24 & -2.14 & -6.37 & -12.23 & Negative \\
Par MMF & -0.57 & -0.65 & -7.71 & -13.22 & Negative \\
Par REP & -2.14 & -2.14 & -13.3 & -14.52 & Negative \\
Par DS & -1.82 & -2.15 & -13.38 & -13.38 & Negative \\
C. V. MacKinnon $1 \%, 5 \%, 10 \%$ & & \multicolumn{2}{c}{ C. V. MacKinnon $1 \%, 5 \%, 10 \%$} \\
& $-4 ;-3.43 ;-3.139$ & & $-3.46 ;-2.87 ;-2.57$ & \\
\hline
\end{tabular}

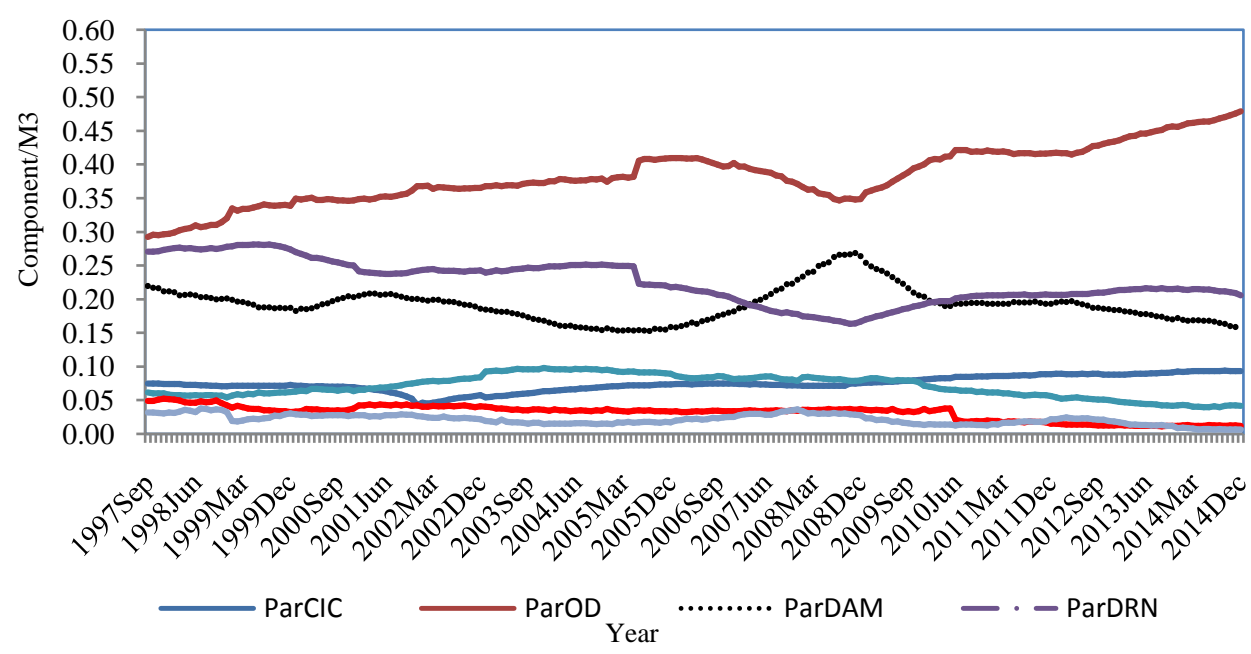

Figure 1. Participation of the components on M3 (\% of each component/M3). Source: Own elaboration based on data from ECB. 
of overnight deposits, deposits with agreed maturity of up to two years and deposits redeemable at notice of up to three months show significant fluctuations from the start of the crisis. Such fluctuations may be related to variables different than interest rates and income.

Figure 1 deserves some additional comments:

First, the participation in M3 of the currency in circulation component (the first line of liquidity aggregate) has steadily increased from 1997 until the end of 2014, and there is no evidence to say that this trend does not continue in the future. The percentage of currency in circulation on aggregate set has doubled during the years of exercise of the common monetary policy by the ECB, going from $5.8 \%$ in 2001 to $9.3 \%$ in 2014 .

Second, the share of overnight deposits has maintained a clear upward trend, going from $29.6 \%$ at the end of 1997 to $47.6 \%$ in late 2014 , i.e., $18 \%$ more. The only downfall of their participation in M3 occurred between March 2006 (40.9\%) and November 2008 (34.9\%), coinciding with higher interest rates over the period, both the interbank market and the Eurosystem.

Third, the share of deposits with agreed maturity of up to 2 years has maintained a gentle downward trend since 1997 (21.7\%) until the end of 2014 (15.9\%), with the exception of the period mentioned in the second point to some extent. The decline in overnight deposits and deposits redeemable at notice of up to three months in 2008 was partially offset by increased deposits with agreed maturity of up to two years.

Fourth, deposits redeemable at notice of up to three months followed a clearly negative trend, from $27.1 \%$ in late 1997 to $20 \%$ in late 2014 .

Fifth, a restructuring of the different assets that make up the broad monetary aggregate ECB reference by agents for the two most liquid assets, currency in circulation and overnight deposits, to the detriment of the less liquid is detected, such as deposits with agreed maturity of up to 2 years and deposits redeemable at notice of up to three months, as well as the other three of less participation. Currency in circulation and overnight deposits, as a whole, amounted in the composition of M3 from 36\% in 1998 to $57.3 \%$ in December 2014, a more than $21 \%$ increase.

The minor assets in terms of participation, such as repurchase agreements, money market fund shares and debt securities with a maturity of up to two years have negatively evolved from $14.2 \%$ in 1997 to $6.2 \%$ in 2014 .

In summary, of the seven components of $\mathrm{M} 3$ it has increased the share of currency in circulation and overnight deposits (together 21.3\%) and reduced that of the remaining five components, without exception.

Table 5 summarizes the results of the ADF and PP tests to interest rates, production, inflation and unemployment. All are non-stationary series in levels and stationary series in first differences. Consequently, the series in levels are integrated of order 1 . They present negative trend, except the IPI (industrial production index) and the unemployment rate.

\section{Cointegration Analysis Data Sets}

In order to determine the possible existence of long-term relationship between each of 
the components of M3 (and its participations) and macroeconomic variables a cointegration analysis is performed using the methodology developed by Johansen (1988. 1991) [24], [25]. This method allows us to estimate maximum likelihood by all cointegrating vectors existing among a set of variables $\mathrm{N}$; provides contrasts with statistics that have well defined limit distributions of the number of cointegrating vectors that are significant. This method does not have the disadvantage of two stage method by Engle and Granger (1987) [26] whose statistics lack well defined limit distributions. At the same time, it offers contrasts of linear restrictions on the parameters that comprise these vectors (see Anchuelo. 1993) [27].

As it is indicated above, all series used are I (1), i.e., have the same degree of integration; requirement for all series to meet. If the dependent variable were I (1), that is to say, the explanatory variables may not be I (0). Otherwise, the equation would be wrongly specified.

The Johansen cointegration tests are performed by pairs of variables. The pairs consist of a component of M3 (or the participation of a component in the broad aggregate) and production, unemployment, inflation and interest rates (Eonia, three-month Euribor and one-year Euribor). Participation in money market funds, debt securities of up to two years and repurchase agreements, due to its small share, are excluded. Table 6 contains the results.

In Table 6, it is shown in bold pairs of variables from which there is a cointegrating relationship, both through the trace statistic and the maximum eigenvalue. Of all the components of M3, deposits with agreed maturity of up to two years are cointegrated with the three selected interest rates, with the rate of economic growth and inflation. When the shares of the different M3 components are analyzed, there is a cointegrating relationship with all the variables used in the case of participation of overnight deposits. Moreover, deposits with agreed maturity of up to two years are cointegrated with the

Table 5. ADF and PP tests: interest rate, production, inflation and unemployment.

\begin{tabular}{cccccc}
\hline \multirow{2}{*}{ Series } & \multicolumn{2}{c}{ Levels } & \multicolumn{2}{c}{ First differences } & \multirow{2}{*}{ Trend } \\
\cline { 2 - 5 } & ADF & PP & ADF & PP & \\
\hline Eurb 3 m & -2.41 & -2.23 & -6.78 & -6.84 & Negative \\
Eurb 1 y & -2.42 & -2.22 & -7 & -7.15 & Negative \\
Eonia & -2.33 & -2.34 & -8.64 & -13.79 & Negative \\
MROR & -1.28 & -1.28 & -6.26 & -11.98 & Negative \\
IPI & -1.62 & -2.03 & -8.51 & -15.68 & Positive \\
Unemployment & -1.76 & -0.856 & -5.45 & -5.58 & Positive \\
Inflation & -1.47 & -2.20 & -7.88 & -12.71 & Negative \\
Core inflation & -1.78 & -1.8 & -16.49 & -16.36 & Negative \\
C. V. MacKinnon & $1 \%, 5 \%, 10 \%$ & & C. V. MacKinnon $1 \%, 5 \%, 10 \%$ \\
& $-4 ;-3.43 ;-3.139$ & & $-3.46 ;-2.87 ;-2.57$ & \\
\hline
\end{tabular}


Table 6. Johansen cointegration tests.

\begin{tabular}{|c|c|c|c|c|c|c|}
\hline & \multicolumn{6}{|c|}{ Trace statistic } \\
\hline & Eonia & Eurb $3 \mathrm{~m}$ & Eurb 1 y & IPIV & Unemp & $\pi$ \\
\hline $\mathrm{CIC}$ & 11.75 & 12.10 & 9.88 & 9.01 & 7.08 & 7.12 \\
\hline OD & 12.18 & 11.25 & 10.99 & 19.65 & 7.40 & 18.25 \\
\hline DAM & 24.26 & 28.78 & 22.97 & 25.48 & 16.84 & 26.60 \\
\hline DRN & 14.42 & 13.25 & 13.55 & 22.09 & 22.09 & 6.54 \\
\hline Par CIC & 15.81 & 15.96 & 15.83 & 8.73 & 6.66 & 5.85 \\
\hline Par OD & 19.46 & 22.26 & 23.52 & 19.32 & 18.12 & 26.29 \\
\hline Par DAM & 13.04 & 13.16 & 11.40 & 33.20 & 31.54 & 30.78 \\
\hline \multirow[t]{4}{*}{ Par DRN } & 11.65 & 11.01 & 10.65 & 20.79 & 12.19 & 11.06 \\
\hline & \multicolumn{6}{|c|}{ Critical value of Osterwald-Lenum at 5\%: 15.49} \\
\hline & \multicolumn{6}{|c|}{ Statiscal maximum eigenvalue } \\
\hline & Eonia & Eurb $3 \mathrm{~m}$ & Eurb 1 y & TVIPI & Unemp & $\pi$ \\
\hline $\mathrm{CIC}$ & 11.10 & 12.07 & 8.95 & 7.7 & 6.25 & 5.15 \\
\hline OD & 10.87 & 9.86 & 9.30 & 19.24 & 5.98 & 16.00 \\
\hline DAM & 21.97 & 15.49 & 21.18 & 23.63 & 14.84 & 22.95 \\
\hline $\mathrm{DRN}$ & 13.12 & 13.15 & 13.51 & 21.65 & 8.25 & 6.41 \\
\hline Par CIC & 15.02 & 15.37 & 14.36 & 8.49 & 6.11 & 5.81 \\
\hline Par OD & 18.27 & 21.26 & 23.07 & 17.71 & 17.21 & 26.28 \\
\hline Par DAM & 9.81 & 9.81 & 7.86 & 28.00 & 22.63 & 27.43 \\
\hline \multirow[t]{2}{*}{ Par DRN } & 9.10 & 8.46 & 7.98 & 18.73 & 10.73 & 8.45 \\
\hline & \multicolumn{6}{|c|}{ Critical value of Osterwald-Lenum at 5\%: 14.26} \\
\hline
\end{tabular}

growth rate (or unemployment) and inflation, but not with interest rates. Finally, the participation of currency in circulation is cointegrated with interest rates, but not with the variables of the activity and prices.

In Section 3, we have seen that the data series of the components of M3, production, inflation and interest rate are not stationary in levels (random walk). However all series are stationary in first differences. All the series used both on the monetary aggregate M3 components as those relating to interest rates, prices, production and unemployment, are integrated series of the same order (order 1). In Section 4, we have seen that the main components of $\mathrm{M} 3$ and relevant variables of production, inflation and interest rates are cointegrated. Herefore, we can estimate the relationship between the different components of $\mathrm{M} 3$ and representative variables of production, interest rates and prices through least-squares regression (OLS) and through the method Stock Watson (DOLS).

\section{Components of M3, Inflation, Interest Rates and Growth: A Regression Analysis OLS}

In this section, we estimate the relationship between participation of the components in M3 that are co-integrated with interest rates and the growth rate of production (as 
proxy. the unemployment rate) and the inflation rate. As seen in Table 6, this condition is only fulfilled for participation of overnight deposits. Meanwhile, the share of currency in circulation is co-integrated with interest rates but not with the variables of the activity or inflation. Additionally, we estimate the relationship between those participations which, although not cointegrated with interest rates, they are with the growth rate (or its proxy) and the rate of inflation. This is the case of the participation of deposits with agreed maturity of up to two years. Finally, deposits redeemable at notice of up to three months keep a cointegrating relationship with the growth rate. The estimated equation is:

$$
C_{a_{t}}=\beta_{0}+\beta_{1} x_{1}+\beta_{2} x_{2}+\cdots+\gamma D_{1}+\varepsilon
$$

where $C_{a}$ is the dependent variable (the share of each component in M3), $x_{i}$ macroeconomic variables (interest rates. economic activity and inflation), $D_{1}$ is a dummy variable and $\mathcal{E}$ is the random disturbance.

The dummy variable (one additive outlier), is defined as:

$$
D_{1}=\left\{\begin{array}{l}
1 \text { if there is instability } \\
0 \text { if there is no instability }
\end{array}\right.
$$

As periods of instability, we select those in which interest rates in the interbank market to different deadlines and the official interest rates of the ECB (intervention rates) have sharp declines related to lower rates of growth in the eurozone (June 2001February 2003) and/or/instability in the financial markets (August 2008-July 2009 and November 2011-June 2014). The last two periods of instability match the turbulence in financial markets as the ECB itself (2009) [28] and ECB (2012) [29] indicated. These periods coincide with the start of unconventional monetary policies (quantitative easing) and other situations of instability/related to public debt and deficits in some Eurozone member countries.

Table 7(a) and Table 7(b) summarize the results of the estimates of Equation (1). The dependent variable in each case is the share or participation of the asset indicated in M3. The independent variables are those maintaining a cointegrating relationship with the chosen dependent variable. In all cases, the coefficients of interest rates and the growth rate have the right sign and are significant at the $1 \%$. Significantly, the dummy variable is also significant to a level of between $1 \%$ and $5 \%$, depending on the case.

\section{Estimates through the Method of Stock Watson (DOLS)}

In this section, the estimates are made through an alternative approach proposed by Stock and Watson (1993) [30], the method called dynamic OLS (DOLS), which has certain advantages over the traditional OLS method. Johansen's method is exposed to the problem that the estimated parameters in an equation are affected by any incorrect specification in other equations. The Stock Watson method is a robust approach to a single equation, which corrects endogeneity of returns by including leads and lags of the first differences of the regressors. It also has the same properties of the asymptotic optimality than those in Johansen distribution. 
Table 7. Estimations of shares in M3.

(a)

\begin{tabular}{cccccc}
\hline & Const. & Eurb 1 y & IPI & $\pi$ & Dummy \\
\hline \multirow{2}{*}{ Par OD } & $c$ & $\beta_{1}$ & $\beta_{2}$ & $\beta_{3}$ & $\gamma$ \\
& 0.43 & $-0.02^{* * *}$ & $0.002^{* * *}$ & $0.011^{* * *}$ & $0.0087^{* *}$ \\
& $(0.004)$ & $(0.001)$ & $(0.0004)$ & $(0.002)$ & $(0.004)$ \\
Par CIC & 0.087 & $0.0048^{* * *}$ & & & $0.0032^{* * *}$ \\
& $(0.001)$ & $(0.00044)$ & & & $(0.001)$ \\
Par DAM & 0.17 & & $-0.003^{* * *}$ & $0.1106^{* * *}$ & $-0.0067^{*}$ \\
& $(0.0037)$ & & $(0.0004)$ & $(0.0019)$ & $(0.0038)$ \\
\hline
\end{tabular}

Std. errors in parentheses. ${ }^{* * *},{ }^{* *}$, ${ }^{*}$ significance at $0.01,0.05$ and 0.10 .

(b)

\begin{tabular}{cccccc}
\hline & Const. & Eonia & $\mu$ & $\pi$ & Dummy \\
\hline \multirow{2}{*}{ Par OD } & $c$ & $\beta_{1}$ & $\beta_{2}$ & $\beta_{3}$ & $\gamma$ \\
& 0.52 & $-0.026^{* * *}$ & $-0.008^{* * *}$ & $0.013^{* * *}$ & $0.0064^{* *}$ \\
& $(0.02)$ & $(0.001)$ & $(0.002)$ & $(0.0022)$ & $(0.003)$ \\
Par CIC & 0.088 & $-0.0054^{* * *}$ & & & $-0.0035^{* * *}$ \\
& $(0.001)$ & $(0.00038)$ & & & $(0.001)$ \\
Par DAM & 0.283 & & $-0.009^{* * *}$ & -0.0025 & $0.0178^{* * *}$ \\
& $(0.016)$ & & $(0.0015)$ & $(0.002)$ & $(0.0036)$ \\
\hline
\end{tabular}

Std. errors in parentheses. ${ }^{* * *}{ }^{* *},{ }^{*}$ significance at $0.01,0.05$ and 0.10 .

The equation is defined as:

$$
C_{a_{t}}=X_{t} M^{\prime}+\sum_{i=-m}^{i=m} \phi_{i} \Delta X_{1_{t-i}}+\sum_{i=-n}^{i=n} \phi_{i} \Delta X_{2_{t-i}}+\cdots+\varepsilon
$$

where $M=\left[\beta_{0}, \beta_{1}, \beta_{2} \cdots \gamma\right] ; X=\left[1, X_{1_{t}}, X_{2_{t}} \cdots D_{1}\right]$ and $m$ and $n$ are the lags and leads of the regressors.

As it was shown in Table 2 and Table 3, all series used are integrated of order one, I (1). Moreover, Table 4 summarizes the results of the coin-integration Johansen test. Under the assumption of cointegration, DOLS estimates are asymptotically efficient and equivalences of the maximum likelihood from Johansen estimates [30].

Equation (2) is estimated by DOLS method for shares of M3 having cointegrating relations with interest rates and/or variables representative of economic activity (IPI and unemployment) and inflation. These conditions are fulfilled in the case of participation of currency in circulation with interest rates; in the case of the participation of deposits with agreed maturity of up to two years with the IPI variables, unemployment and inflation; in the case of overnight deposits with all variables. The results did not undergo significant changes when you choose either type of interest. They are alternatively used the one-year Euribor and Eonia short rate. Table 8(a) and Table 8(b) show the results. 
Table 8. Results DOLS.

(a)

\begin{tabular}{|c|c|c|c|c|c|c|}
\hline & c & eurb 1 y & IPI & $\pi$ & Dummy & $\mathrm{R}^{2}$ \\
\hline \multirow[b]{2}{*}{ Par CIC } & 0.10 & $-0.009^{* * *}$ & & & $-0.087^{* *}$ & \multirow[b]{2}{*}{0.90} \\
\hline & $(0.004)$ & $(0.001)$ & & & $(0.04)$ & \\
\hline \multirow{2}{*}{ Par OD } & 0.356 & $-0.018^{* * *}$ & $-0.10^{* * *}$ & $0.04^{* * *}$ & $0.030^{* * *}$ & \multirow{2}{*}{0.96} \\
\hline & $(0.022)$ & $(0.003)$ & $(0.002)$ & $(0.008)$ & $(0.01)$ & \\
\hline \multirow{2}{*}{ Par DAM } & 0.183 & $0.0117^{* * *}$ & $-0.011^{* * *}$ & $-0.013^{* * *}$ & $0.032^{* * *}$ & \multirow{2}{*}{0.98} \\
\hline & $(0.014)$ & $(0.0019)$ & $(0.0019)$ & $(0.005)$ & $(0.012)$ & \\
\hline \multicolumn{7}{|c|}{ (b) } \\
\hline & c & Eonia & $\mu$ & $\pi$ & Dummy & $\mathrm{R}^{2}$ \\
\hline \multirow{2}{*}{ Par CIC } & 0.095 & $-0.008^{* * *}$ & & & $-0.006^{* *}$ & \multirow[t]{2}{*}{0.78} \\
\hline & $(0.002)$ & $(0.00078)$ & & & $(0.003)$ & \\
\hline \multirow{2}{*}{ Par OD } & 0.634 & $-0.034^{* * *}$ & $-0.02^{* * *}$ & $0.0076^{* *}$ & $0.04^{* * *}$ & \multirow[t]{2}{*}{0.99} \\
\hline & $(0.033)$ & $(0.0028)$ & $(0.0021)$ & $(0.004)$ & $(0.006)$ & \\
\hline \multirow{2}{*}{ Par DAM } & 0.374 & $0.025^{* * *}$ & $-0.0083^{* *}$ & $-0.083^{* * *}$ & $0.02^{* *}$ & \multirow[t]{2}{*}{0.99} \\
\hline & $(0.054)$ & $(0.004)$ & $(0.004)$ & $(0.006)$ & $(0.10)$ & \\
\hline
\end{tabular}

Std. error between parentheses. ${ }^{* * *},{ }^{* *}$, ${ }^{*}$ significance at $0.01,0.05$ and 0.10 , respectively. Lags and leads automatic specification Akaike (AIC). Long term variance estimation: Bartlett kernel, Newey-West (bandwidth 50,000).

From the results in Table 8(a) and Table 8(b), it is clear that the coefficients of all regressors (all the estimates made through the DOLS method), are significant at the $1 \%$, except in very limited cases where the significance level is 5\%. The sign of each item was the expected one. For example, the interest rate and overnight deposits and currency in circulation move in opposite directions, while the rest of deposits do it in the same direction. The dummy variable is selected, in all cases, significant. The coefficients of determination $\left(R^{2}\right)$ are high, above 0.90 , except the dummy variable in the case of participation in M3 of currency in circulation, when taken the Eonia as the interest rate, in which case $\mathrm{R}^{2}=0.78$.

\section{Conclusions}

The broad monetary aggregate M3 has not had the expected evolution that the ECB is estimated as compatible with the inflation target "very close to $2 \%$ " annually. Between 1999 and 2008, the annual growth rates that reached $12 \%$, far exceeded the range between $4 \%$ and $5 \%$ set by reference. Following the crisis, the growth rate of M3 declined sharply since January 2007, reaching negative rates between October 2009 and June 2010. Since the end of 2010, it has been located at an average of around $2 \%$, far below the reference value. Broad monetary aggregate M3 did not work as a good leading indicator of inflation expectations, although it worked well as a leading indicator of the crisis, according to the theory of cycles. However, there is consensus among economists 
about the success of the ECB in controlling inflation since 1999.

Our work focuses on the behavior of the various components of M3, rather than the aggregate as a whole. The DOLS estimates show that the explanatory variables that are cointegrated with the participation of the various components of M3 have a high explanatory power, as shown by the coefficient of determination $\mathrm{R}^{2}$. In turn, the dummy additive outlier used for periods of instability considered is significant in all cases. So they are all explanatory variables at the 0.01 level.

A restructuring of the different assets that make up the broad monetary aggregate ECB reference by agents for the two most liquid assets, currency in circulation and overnight deposits, to the detriment of the less liquid is detected, such as deposits with agreed maturity of up to 2 years and deposits redeemable at notice of up to three months, as well as the other three of less participation. Currency in circulation and overnight deposits, as a whole, amounted in the composition of M3 from 36\% in 1998 to $57.3 \%$ in December 2014, a more than $21 \%$ increase. We believe that, especially since the onset of the financial crisis, agents have concentrated assets in the most liquid components of M3. Uncertainty and instability in financial markets may be at the origin of this behavior.

At this point, we can conclude that it is producing a constant translation towards more liquid assets, regardless of the evolution of variables that explain the behavior of money demand and tenure liquidity against holding less liquid earning assets. The search for the causes of this behavior trend increase in liquidity within a monetary aggregate, intended as a leading indicator for the stability-oriented monetary policy strategy of the Eurosystem, should be the goal of future research. If there is a change in the behavior of agents in this direction, the implementation of monetary policy should be taken into account, since the effects on macroeconomic variables will be modified. According to the ECB itself, the financial turbulence has increased uncertainty about future economic and financial developments. The increase in the most liquid assets can rest upon the uncertainty and mistrust due to the precaution reason.

\section{References}

[1] ECB (1999) The Stability-Oriented Monetary Policy Strategy of the Eurosystem. Monthly Bulletin, January 1999, 39-50.

[2] ECB (2000) The Two Pillars of the ECB’s Monetary Policy Strategy. Monthly Bulletin, November $2000,37-48$.

[3] Poole, W. (1994) Monetary Aggregates Targeting in a Low-Inflation Economy. In: Fuhrer, J.C., Ed., Goals, Guidelines, and Constraints Facing Monetary Policymakers, Federal Reserve Bank of Boston, Boston, 87-121.

[4] Setzer, R. and Wolff, G.B. (2013) Money Demand in the Euro Area: New Insights from Disaggregated Data. International Economics an Economic Policy, 10, 297-315. http://dx.doi.org/10.1007/s10368-012-0214-7

[5] Capasso, S. and Napolitano, O. (2012) Testing for the Stability of Money Demand in Italy: Has the Euro Influenced the Monetary Transmission Mechanism? Applied Economics, 44, 3121-3133. http://dx.doi.org/10.1080/00036846.2011.570719 
[6] Mulligan, C.B. and Sala-i-Martin, X. (1992) US Money Demand: Surprising Cross-Sectional Estimates. Brookings Papers on Economic Activity, Economic Studies Program. The Brookings Institution, 23, 285-343. http://dx.doi.org/10.2307/2534585

[7] Nautz, D. and Rondorf, U. (2011) The (In)stability of Money Demand in the Euro Area. Lessons from a Cross Country Analysis. Empirica, Skpringer, 38, 539-553.

[8] Foresti, P. and Napolitano, O. (2013) Modeling Long-Run Money Demand: A Panel Data Analysis on Nine Developed Economies. Applied Financial Economics, 23, 1707-1719. http://dx.doi.org/10.1080/09603107.2013.848024

[9] Dreger, C., Reimers, H.E. and Roffia, B. (2007) Long-Run Money Demand in the New EU Member States with Exchange Rate Effects. Eastern European Economics, 45, 75-94. http://dx.doi.org/10.2753/EEE0012-8775450204

[10] Arnold, I.J. and Roelands, S. (2010) The Demand for Euros. Journal of Macroeconomics, 32, 674-684. http://dx.doi.org/10.1016/j.jmacro.2010.01.001

[11] Hamori, S. and Hamori, N. (2008) Demand for Money in the Euro Area. Economic Systems, 32, 274-284. http://dx.doi.org/10.1016/j.ecosys.2008.03.001

[12] Mark, N.C. and Sul, S. (2003) Cointegration Vector Estimation by Panel DOLS and LongRun Money Demanda. Oxford Bulletin of Economics and Statistics, 65, 655-680. http://dx.doi.org/10.1111/j.1468-0084.2003.00066.x

[13] Rao, B.B., Tamazian, A. and Singh, P. (2009) Demand for Money in the Asian Countries: A Systems GMM Panel Data Approach and Structural Breaks. MPRA Paper 15030, University Library of Munich, Munich.

[14] Hamori, S. and Tokihisa, A. (2001) Seasonal Cointegration and the Money Demand Function: Some Evidence from Japan. Applied Economics Letters, 8, 305-310. http://dx.doi.org/10.1080/135048501750157468

[15] Harb, M. (2004) Money Demand Function: A Heterogeneous Panel Application. Applied Economics Letters, 11, 551-555. http://dx.doi.org/10.1080/1350485042000225739

[16] Dreger, C. and Wolters, W. (2010) Investigating M3 Money Demand in the Euro Area. Journal of International Money and Finance, 29, 111-122. http://dx.doi.org/10.1016/j.jimonfin.2009.02.002

[17] ECB (1999) Euro Area Monetary Aggregates and Their Role in the Eurosystem's Monetary Policy Strategy. Monthly Bulletin, February 1999, 29-46.

[18] Beyer, A., Fischer, B. and Landesberger, J. (2007) M3 Demand Stability: Implications for the Usefulness of Money in Monetary Policy Making. ECB, EUROSYSTEM. MPC/035/07.

[19] Fischer, B., Lenza, M., Pill, H. and Reichlin, L. (2007) Monetary Analysis and Monetary Policy in the Euro Area 1999-2006. Journal of International Money and Finance, 25, 11381164.

[20] Gerlach, S. and Svensson, L.E.O. (2003) Money and Inflation in the Euro Area: A Case for Monetary Indicators? Journal of Monetary Economics, 50, 1649-1672. http://dx.doi.org/10.1016/j.jmoneco.2003.02.002

[21] Foresti, P. and Napolitano, O. (2014) Money Demand in the Eurozone: Do Monetary Aggregates Matter? Inzinerine Ekonomika: Engineering Economics, 25, 497-503.

[22] Dickey, D.A. and Fuller, W.A. (1979) Distribution of the Estimators for Autoregressive Time Series with a Unit Root. Journal of the American Statistical Association, 47, 427-431.

[23] Phillips, P.C.B. and Perron, P. (1988) Testing for a Unit Root in Time Series Regression. Biometrika, 75, 335-346. http://dx.doi.org/10.1093/biomet/75.2.335

[24] Johansen, S. (1988) Statistical Analysis of Cointegration Vectors. Journal of Economic Dy- 
namics and Control, 12, 231-254. http://dx.doi.org/10.1016/0165-1889(88)90041-3

[25] Johansen, S. (1991) Estimation and Hypothesis Testing of Cointegration Vectors in Gaussian Vector Autoregressive Models. Econometrica, 59, 1551-1580.

http://dx.doi.org/10.2307/2938278

[26] Engle, R.F. and Granger, C.W.J. (1987) Cointegration and Error Correction: Representation, Estimation and Testing. Econometrica, 55, 251-276. http://dx.doi.org/10.2307/1913236

[27] Anchuelo, A. (1993) Series integradas y cointegradas: Una introducción. Revista de Economía Aplicada, 1, 151-164.

[28] ECB (2009) Monetary Analysis in an Environment of Financial Turmoil. Monthly Bulletin, November 2009, 81-96.

[29] ECB (2012) Money and Credit Growth after Economic and Financial Crises-A Historical Global Perspective. Monthly Bulletin, February 2012, 69-85.

[30] Stock, J. and Watson, M.W. (1993) A Simple Estimator of Cointegrating Vectors in Higher Order Integrate Systems. Econometrica, 61, 783-820. http://dx.doi.org/10.2307/2951763

Submit or recommend next manuscript to SCIRP and we will provide best service for you:

Accepting pre-submission inquiries through Email, Facebook, LinkedIn, Twitter, etc.

A wide selection of journals (inclusive of 9 subjects, more than 200 journals)

Providing 24-hour high-quality service

User-friendly online submission system

Fair and swift peer-review system

Efficient typesetting and proofreading procedure

Display of the result of downloads and visits, as well as the number of cited articles

Maximum dissemination of your research work

Submit your manuscript at: http://papersubmission.scirp.org/ 